\title{
BRIEF
}

\section{Use of Digital vs Printed Posters for Teaching and Learning in Pharmacy Education}

\author{
Lydia C. Newsom, PharmD, Susan W. Miller, PharmD, Melissa Chesson, PharmD \\ Mercer University, College of Pharmacy, Atlanta, Georgia \\ Submitted July 24, 2020; accepted January 8, 2021; published June 2021.
}

Objective. To characterize student pharmacists' perceptions of the use of posters as a learning tool and their preferences regarding digital posters compared to printed posters for presentation and review.

Methods. Student pharmacists presented and peer-reviewed posters in a digital format using a tablet and an overhead monitor or in a printed format mounted on a poster board. The perceptions of two cohorts of pharmacy students were characterized by comparing their responses on pre- and post-activity surveys.

Results. The pre- and post-activity surveys were completed by 543 students (95.3\%) in the 2017-2018 academic year and 553 students (97\%) in the 2018-2019 academic year, respectively. Over 95\% of students perceived that the poster activity enhanced their poster creation, literature evaluation, and communication skills, while also improving their learning of pharmacy-related topics. There was a significant increase on the post-activity survey in the number of students who preferred the digital poster format, with students indicating that the digital format was straightforward (87.3\%), enhanced their presentation(77.2\%), and promoted learning $(70.5 \%)$.

Conclusion. Poster presentations provide a platform for the dissemination and discussion of topics and allow students to improve their presentation and communication skills. Digital posters represent a convenient, cost-effective, and preferred presentation method for pharmacy students compared to printed posters.

Keywords: poster, technology, virtual

\section{INTRODUCTION}

The poster is an educational tool and information source for presentation in live or standalone format. The posterhas beenused in post-secondary education to promote student interaction and learning. ${ }^{1,2}$ In pharmacy education, student-created posters positively impact perceptions of learning related to drug information skills, awareness of public health issues, and communication skills. ${ }^{2,3}$ Pharmacy graduates must be able to effectively evaluate and communicate scientific literature findings and clinical information. ${ }^{4,5}$ A student-created poster presentation focusing on scientific literature analysis and how findings can be applied to patient care is an educational strategy targeting the "communicator" and "information master" domains.

Presentations using printed posters are an important activity at academic conferences. The printed format may have outgrown its effectiveness in terms of enabling conference attendees to select and interact with others' work. ${ }^{6-9}$ The time constraints of a live, printed poster session are

Corresponding Author: Susan W. Miller, Mercer University, College of Pharmacy, 3001 Mercer University Dr., Atlanta, GA 30341-4115. Tel: 678-547-6217.Email: Miller_sw@mercer.edu inflexible, and consideration should be given as to how to increase the availability of posters to interested peers. ${ }^{8} \mathrm{De}$ Simone and colleagues proposed a system for holding digital poster sessions at conferences. ${ }^{10}$ Reported advantages of the digital format include lower production costs, ease of preparation and transport, dissemination to a larger audience, and large archival capabilities. Medical conferences report increasing use of digital or virtual poster sessions, but few studies have assessed their usefulness and effectiveness. $^{11}$

Faculty at Mercer University College of Pharmacy developed a poster assignment in the Practice of Pharmacy courses, a series of six longitudinal application-based courses delivered over the first three years of the four-year Doctor of Pharmacy curriculum. The assignment targeted development of skills in the previously mentioned educational domains and included the creation, presentation, discussion, and peer review of posters. For over 10 years, the assignment required students to create and present a printed poster. In 2017, the digital poster format was included to introduce students to this emerging presentation modality. The investigators hypothesized that the digital poster format would be similar to the printed poster format with regard to teaching and learning, but that students might prefer the 


\section{American Journal of Pharmaceutical Education 2021; 85 (6) Article 8307.}

digital format because of its ease of use and enhanced functionality of just-in-time editing, zooming, scrolling, and portability. The objectives of this study were to characterize student pharmacists' perceptions of the use of posters as a learning tool and their preferences regarding digital posters compared to printed posters for presentation and review.

\section{METHODS}

This study included first- and third-professional year (P1 and P3) pharmacy students during the 2017-2018 and 2018-2019 academic years. At the beginning of the academic year, faculty oriented students to the poster assignment and provided them with an example poster, a poster template, grading rubric, and detailed instructions regarding the presentations and peer review process. Faculty assigned students to poster presentation groups consisting of three or four students in the same professional year. Within these groups, students presented one printed or digital poster to their peers and peer reviewed their other group members' posters. The poster sessions occurred throughout the yearlong course sequence. During a poster session, one student presented their poster while the remaining group members used the grading rubric to peer review the presentation. Student presenters were assigned a grade based on faculty review using the same grading rubric. The rubric assigned points to poster format; poster content; use of visual aids, such as tables or figures; originality; application of content to patient care; and the presenter's communication skills. Students also received a grade for the peer review that they provided for their peer's presentation. The poster activities counted as $5 \%$ and $10 \%$ of the cumulative course grade for P1 and P3 students, respectively. While individual students presented either a digital or printed poster, all students reviewed both digital and printed poster presentations.

P1 students' posters reviewed literature associated with a commonly prescribed medication. P3 students' posters reviewed a landmark clinical trial and discussed its application to patient care. Students used a standardized template for both poster formats and submitted a PDF version of the poster electronically via the learning management system (LMS). Academic support personnel printed posters for students to display on an assigned presentation board. Students accessed the PDF of the digital posters via LMS using a college-owned Apple iPad connected to a mounted video monitor in a designated space. Use of the iPad for delivering presentations was detailed during activity orientation. Printed instructions were also provided. The iPad allowed presenters to use zoom and scrolling capabilities to highlight aspects of their digital poster during their presentation. Animation capabilities were not available to use in the digital posters.
Students completed a 14-item pre-survey that included demographic items and items on students' baseline experience and perceptions of tablets and posters. The 26-item post-survey included the pre-survey questions and additional questions to assess student perceptions of the poster formats. The surveys included multiple-choice and fourpoint Likert-scale items and were administered using SurveyMonkey (SurveyMonkey, Inc) at the beginning and end of the yearlong course sequence. Investigators used descriptive statistics, the Wilcoxon signed rank test, and the Pearson chi-square test to compare the pre-and post-survey instruments using a significance level of $p<.05$. Data analysis was conducted using the Statistical Package for the Social Sciences (IBM). This study was deemed exempt by the Mercer University Institutional Review Board.

\section{RESULTS}

There were 280 P1 and 290 P3 students enrolled in the study during the two-year study period. Pre- and post- surveys were completed by 543 students $(95.3 \%)$ in the 2017-2018 academic year and 553 students (97\%) in the 2018-2019 academic year, respectively. Most students (88.4\%) were 20 to 29 years of age, and approximately $67 \%$ were female. The majority of students owned a tablet device at baseline (64.3\%) and 67.4\% used the tablet for academic or professional purposes. The most common tablet used was the iPad (58.1\%). At baseline, more students had experience with creating or presenting a printed poster than a digital poster $(66.5 \%$ vs $24.1 \%$, respectively). Student perceptions of posters as a learning tool are described in Figure 1. A majority of the students reported the poster activity enhanced their knowledge of poster creation, helped them organize and critically evaluate scientific information, and improved their presentation and communication skills. Students also noted having more confidence and increased likelihood of presenting a poster at a professional meeting after completing the activity. Student perceptions of digital poster presentations are detailed in Figure 2. The majority of students perceived that use of the iPad to present a digital poster was straightforward, enhanced their presentation, and enhanced student learning. To assess the change in student perceptions during the study period, student pre- and post-survey data were paired for 382 students $(69 \%)$ who provided consistent study participant identification (Figure 3). After the poster activity, the majority of students affirmed the usefulness of posters for learning, and significantly more students preferred digital posters over printed posters. Neither student perceptions regarding poster utility nor student preference for digital posters were associated with age, gender, professional year, or tablet ownership at baseline. 


\section{American Journal of Pharmaceutical Education 2021; 85 (6) Article 8307.}

Enhanced my knowledge of how to create a professional poster.

Improved my poster presentation and/or communication skills.

Enhanced my ability to critique a poster presentation.

Helped me to organize and critically evaluate scientific information and/or the medical literature.

I am more confident in my ability to develop a poster for presentation at a professional meeting after the poster presentation activity.

I am more likely to develop a poster for presentation at a professional meeting after the poster presentation activity.

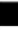
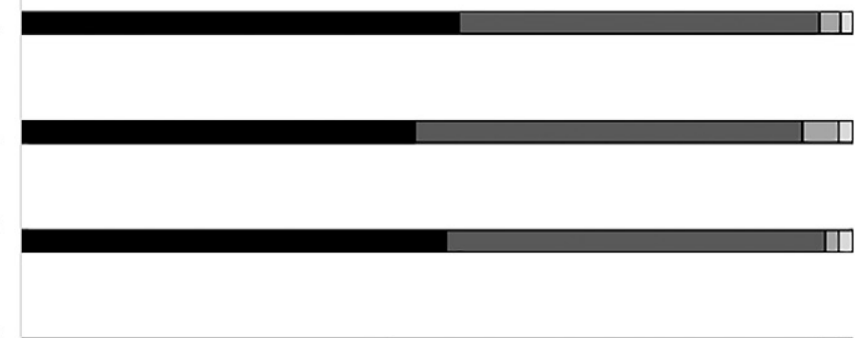

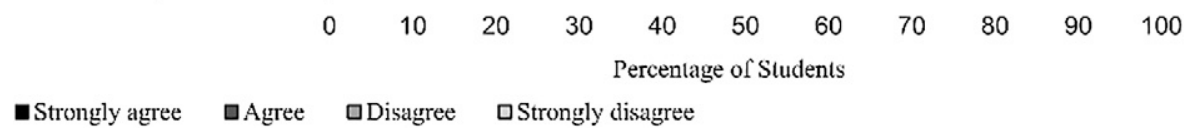

Figure 1. Pharmacy Student Perceptions of Posters as a Learning Tool $(n=553)$

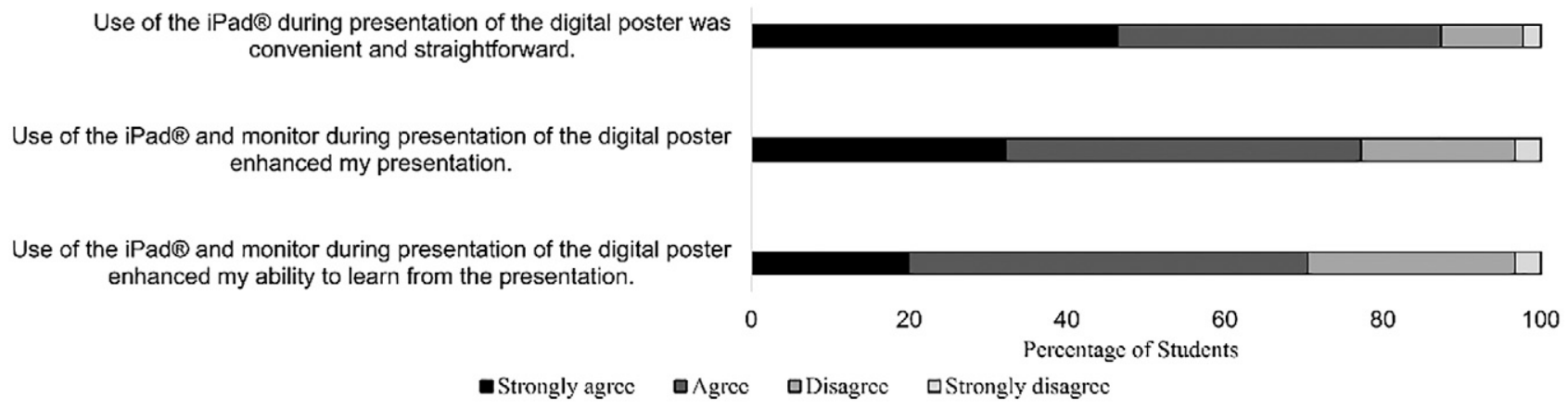

Figure 2. Pharmacy Students' Perceptions Regarding the Use of iPads for Creating and Sharing Digital Posters ( $=553)$

\section{DISCUSSION}

Student perceptions were positive regarding the use of posters as a learning tool and platform for discussion of pharmacy-related topics. The majority of students perceived that this educational strategy enhanced their literature evaluation, presentation, and communication skills. These perceptions align with the core domains from the Center for the Advancement of Pharmacy Education (CAPE) outcomes and Entrustable Professional Activities, respectively. ${ }^{4,5}$ Students likely received feedback corresponding to multiple domains as feedback from faculty usually focused on poster construction, literature evaluation, and clinical application, while students usually commented on presentation and communication skills. At the end of the study, more than two-thirds of students preferred the digital poster format. This preference was not associated with student characteristics at baseline. A small subset of students felt that iPad use was inconvenient or not straightforward $(12.7 \%)$. The digital format increased presentation complexity requiring students to access their poster through the LMS and use an iPad throughout the presentation. The prior review of iPad use, printed instructions, and available technology support likely helped many students feel more comfortable with the digital format. Additionally, a faculty member or teaching assistant facilitated device set up for the digital poster presentations. The digital poster format may have also unintentionally interfered with learning during some presentations. When the zoom feature was used for a digital poster, students could not view the entire poster during the presentation. While this may have enhanced student engagement in the presenter's discussion, it may have limited student-directed engagement with the information.

This study adds to the limited pharmacy literature related to the use of posters as a tool for teaching and learning. Our study corroborates findings by Kelsch and colleagues in which pairs of students created a printed poster detailing public health topics for a pharmacy conference. Student perceptions were positive regarding the value of 
American Journal of Pharmaceutical Education 2021; 85 (6) Article 8307.

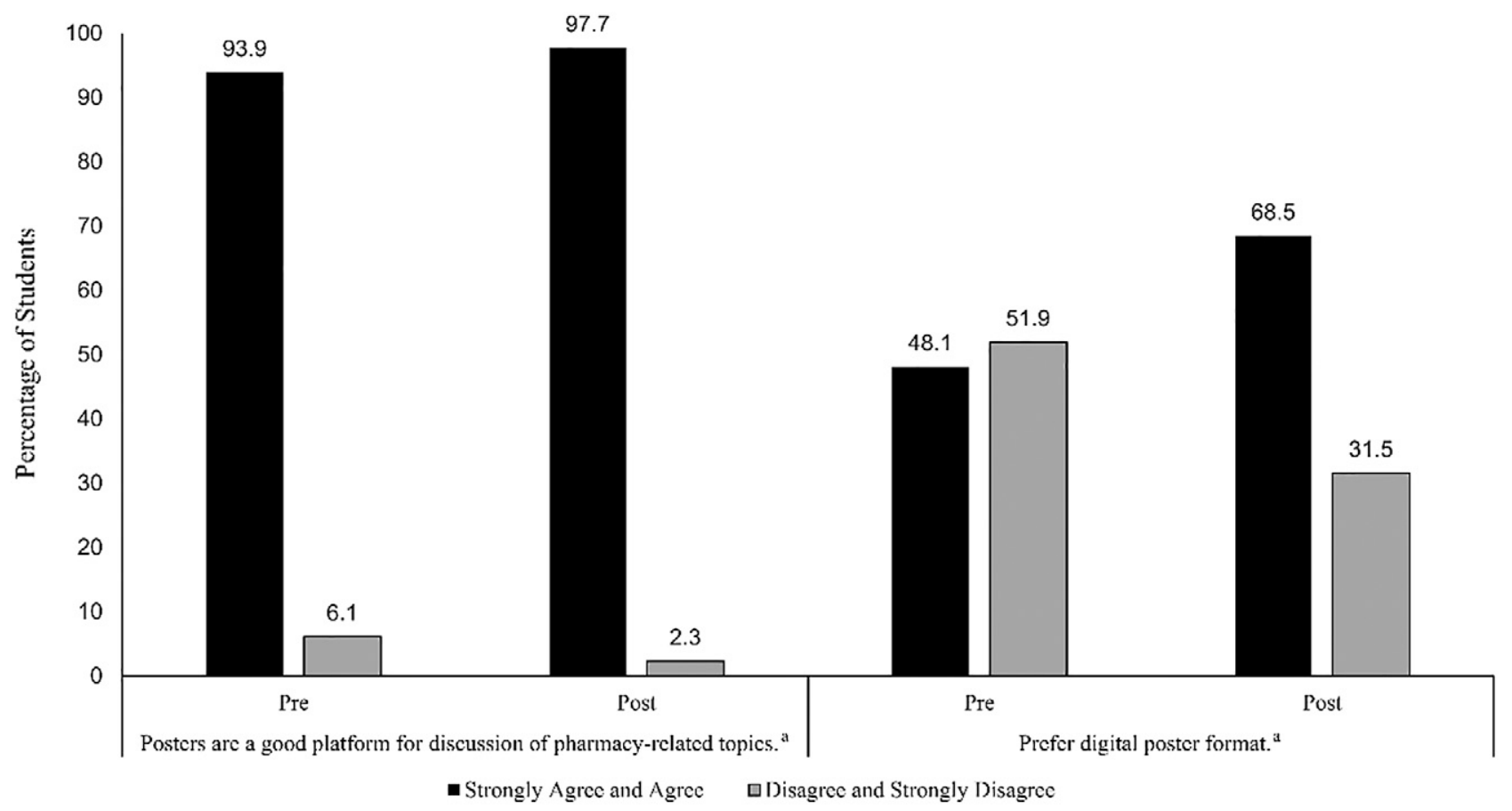

Figure 3. Pharmacy Students' Perceptions of Two Different Methods of Poster Presentation $(n=382)$

${ }^{\mathrm{a}} \mathrm{p}<.05$ for pre- and post-survey comparisons.

the activity in enhancing knowledge and communication skills. ${ }^{3}$ Karimi and colleagues assessed the impact of printed posters on student discussion and learning. ${ }^{2}$ In this study, $42 \%$ of graduating third professional year students worked in teams to develop posters summarizing common disease states for national licensure examination review. The activity was perceived positively, and students who created the posters noted the activity enhanced their knowledge, poster creation, and presentation skills. As in our study, posters detailing a pharmacy-related topic were created by students and used for peer teaching. In contrast, only a subset of students participated in creation of printed posters in the Karimi study. While national licensure examination scores improved for students who participated in the poster activity, other factors could have contributed to this finding. ${ }^{2}$ De Simone and colleagues demonstrated that the digital interactive poster presentation is a viable and well-received platform for information dissemination in the professional setting. Our digital posters preserved the functionality of this format and thus should prepare students for poster presentations at professional conferences in traditional or virtual formats. ${ }^{10}$

Posters are a viable tool for teaching and learning within the pharmacy curriculum. Providing students with a detailed orientation to the poster activity is essential for success. Providing students with a standardized template, such as a PowerPoint slide with the appropriate font, shading, and sizing that should be used in the poster provides structure and the correct dimensions needed for display and printing. An activity rubric can provide the student with clear expectations while also serving as a grading tool. Assigning the same due date for all posters, regardless of presentation date, ensures assignment equity for students and provides additional time for grading. The three course faculty that were involved with this activity did not have a preference regarding poster format for learning, but all valued the electronic poster file for its ease of submission, and allowance of asynchronous viewing and grading to accommodate student and faculty availability.

There are limitations associated with this study. The results obtained were student perceptions, which may have been impacted by personal or professional factors. Qualitative data pertaining to student perceptions were not obtained. In each of the professional years studied, students created and presented either a digital or printed poster. These presentations were scheduled over two semesters, thus some students peer reviewed one or more printed or digital poster presentations prior to delivering their own presentation. Similarly, student exposure to printed and digital posters likely differed slightly based on the number of students in their group, the experience and preparedness of their group members, and the perceptions of other group members regarding poster format. Also, P3 students had experience with presenting printed posters during their P1 year. Student 


\section{American Journal of Pharmaceutical Education 2021; 85 (6) Article 8307.}

preference for poster format was not associated with professional year, suggesting the impact of this prior exposure was minimal. Finally, our ability to pair data during data assessment was limited as many students did not use the same study identifier on the pre- and post- surveys as instructed. Based on these perceptions and the logistics associated with printed posters, all posters within the poster assignment were converted to the digital format during the 2019-2020 academic year. Instead of using an iPad connected to a monitor for poster presentations, students used their personal computer in a small group setting.

\section{CONCLUSION}

The digital poster format offers a cost-effective alternative that decreases personnel time and resource utilization associated with printed posters. The digital format simplifies and enhances information distribution as the poster is almost instantaneously stored and shared without the need for transporting it or physically displaying it. The format is useful for both in-person, socially distanced, or virtual presentations with video and audio features. Asynchronous viewing of a digital poster is also possible, with or without prerecorded commentary from the presenter. Because of the widespread and expanding use of technology, this format is generalizable to almost all educational, clinical, and professional settings. The use of teaching and learning tools that transition to a virtual environment is relevant given the current global pandemic and the need for our students to engage in courses delivered via nontraditional methods. Future studies should assess student learning using the digital format and investigate poster and presentation features associated with enhanced learning. Consideration of techniques for accommodating viewers with disabilities is also of interest as is exploration of faculty perceptions of the use of printed and digital posters in pharmacy education.

\section{ACKNOWLEDGMENTS}

This study was supported by a grant from the Center for Advancement of Teaching and Learning (CATAL) at Mercer University College of Pharmacy.

\section{REFERENCES}

1. Duchin S, Sherwood G. Posters as an educational strategy. J Contin Educ Nurs. 1990;21(5):205-208.

2. Karimi R, Meyer D, Fujisaki B, Stein S. Implementation of an integrated longitudinal curricular activity for graduating pharmacy students. Am J Pharm Educ. 2014;78(6):124.

3. Kelsch MP, Werremeyer AB. Poster project to emphasize public health in the pharmacy curriculum. Am J Pharm Educ. 2011;75(1):2.

4. Accreditation Council for Pharmacy Education. Accreditation Standards and Key Elements for the Professional Program in Pharmacy Leading to the Doctor of Pharmacy Degree ("Standards 2016"). Published February 2015. https://www.acpeaccredit.org/pdf/Standards2016FINAL.pdf. Accessed June 1, 2021.

5. Pittenger AL, Copeland DA, Lacroix MM, et al. Report of the 20162017 Academic Affairs Standing Committee. Am J Pharm Educ. 2017; 81(5):Article S4.

6. Shin SJ. Evaluation of electronic versus traditional format poster presentations. Med Educ. 2012;46:519-520.

7. Brownlie D. Towards effective poster presentations: an annotated bibliography. Eur J Mark. 2007;41(11/12):1245-1283.

8. Rowe N, Ilic D. Rethinking poster presentations at large-scale scientific meetings - is it time for the format to evolve? FEBSJ. 2015;282: 3661-3668.

9. Bell C, Buckley EG, Evans P, Lloyd-Jones G. An evaluation of digital, split-site and traditional formats in conference poster sessions. Med Teach. 2006;28(2):175-179.

10. De Simone R, Rodrian J, Osswald B, Sack FU, De Simone E, Hagl $\mathrm{S}$. Initial experience with a new communication tool: The 'Digital Interactive Poster Presentation'. Eur J Cardiothorac Surg. 2001;19: 953-955.

11. Powell-Tuck J, Leach S, Maccready L. Electronic poster presentations in BAPEN-a controlled evaluation. Clin Nutr; 2002;21(3): 261-263. 